\title{
Algumas plantas cianogenéticas da regiảo amazônica
}

Aura M. Puentes de Diaz (")

Maria Isabel Galdames Portus ( $\left.{ }^{(}\right)$

Marlene Freitas da Silva ( $\left.{ }^{*}\right)$

\section{Resumo}

Dados sobre o teor de ácido cianídrico em 14 capins e métodos físicos para a sua eliminação são apresentados, juntamente com alguns dados botânicos destas e de outras plantas amazônicas.

\section{INTRODUÇÃo}

A ingestão de plantas cianogênicas tem provocado freqüentes mortes em gado e, ocasionalmente, em seres humanos (Seigler, 1975). Isto porque estas plantas sintetizam compostos que liberam ácido cianídrico ( $\mathrm{HCN}$ ), pela ação de enzimas apropriadas, ou de agentes químicos hidrolizantes sobre o vegetal triturado. Esta propriedade, conhecida por cianogênese ganhou importância histórica só com a presença de glicosídios cianogênicos em tecidos de plantas. Sabe-se hoje, que, dois tipos de compostos químicos são responsáveis por esta habilidade : os glicosídios cianogênicos, e os cianolipídios. Ambos sobre hidrólise liberam um componente carbonílico e HCN, quando removido o açúcar ou o ácido graxo (Seigler, 1975; Mikolajczak, 1977).

Os glicosídios cianogênicos ocorrem em aproximadamente, 70 a 80 famílias de plantas, abrangendo fungos, pteridófitas, gimnospermas e angiospermas (tanto monocotiledôneas, como dicotiledôneas) (Seigler, 1975). Os cianolipídios são de distribuição restrita e com pouquíssimas exceções limitam-se aos óleos das sementes de Sapindáceas (Mikolajczak, 1977).

Presume-se porém, que a presença de compostos cianogênicos nas plantas, tem função de excreção, metabolismo de nitrogênio e defesa (Jones, 1972). O conteúdo destes compostos nos vegetais, está determinado por fatores fisiológicos (idade da planta, stress de água, nutrição mineral, sombreamento e espes- sura da casca), e, genéticos (polimorfismo genético) (Butler et al., 1973). No entanto, segundo Jones (1972), dentro de uma mesma espécie é possível encontrar plantas cianogênicas e acianogênicas, variando de lugar para lugar e de habitat para habitat.

As $\beta$-glucosidades da microflora do rúmen dos animais, provocam rapidamente a hidrólise dos compostos cianogênicos dos vegetais ingeridos, e o HCN liberado é incorporado na corrente sangüínea ocasionando intoxicação. Em ovelhas, a dose mínima letal de HCN livre é de $2.4 \mathrm{mg} / \mathrm{kg}$ de peso. A tolerância a doses maiores pode ser atribuída ao tempo requerido para a ingestão das plantas, e, a liberação do $\mathrm{HCN}$. As ovelhas podem tolerar $15-20 \mathrm{mg} \mathrm{HCN} / \mathrm{kg}$ por dia, quando a ingestão da forragem é lenta (Butler et al., 1973). O gado bovino pode manter-se aparentemente tolerante a $50 \mathrm{mg} \mathrm{HCN} / \mathrm{kg}$ durante um dia, mas, a mesma quantidade assimilada em uma hora, é mortal. O fato de uma dose ser ou não ser letal, está associado com processos de detoxificação, os quais em mamíferos são realizados pela enzima rodanese presente em maior grau no fígado. A detoxificação é aeróbica e requer um doador de enxofre (Jonas, 1972).

Segundo Aplin (1975), os sintomas de envenenamento por cianeto em gado são: respiração acelerada e profunda, passando rapidamente à respiração difícil, excitação, suspiros, vertigem, prostração, convulsões, coma e morte. As membranas da mucosa da boca e olhos, tomam cor púrpura.

\section{MATERIAL E MÉTODOS}

Amostras completas de material vegetal fresco foram usadas nas análises qualitativa e quantitativa, e um exemplar foi depositado no herbário do INPA. Todas as plantas foram

$\left({ }^{\bullet}\right)$ - Instituto Nacional de Pesquisas da Amazônia, Manaus. 
coletadas durante os meses de maio e junho de 1977. A maioria dos capins foram coletados no Campus do INPA-Manaus crescendo em solo argiloso de capoeira, com exceção de Homolepis aturensis da Reserva Ducke-Manaus que cresce em solo argiloso e de Brachiaria mutica, Orysa perenis, Hymenachne amplexicaulis, Panicum chloroticum, Paspalum repens e Panicum maximum do lago Janauari. A descrição botânica das plantas foi baseada em bibliografia especializada e a determinação feita por comparação com amostras herborizadas. A seleção destas plantas foi feita pela comprovação indireta da presença de compostos cianogênicos, ou seja, pela detecção do HCN liberado por hidrólise, mediante duas provas qualitativas (Eyjolfsson, 1970):

Teste do acetato de benzidina acetato cúprico: Papel de filtro impregnado com acetado de benzidina-acetado cúprico foi colocado em contato com a planta fragmentada. A coloraçāo azul indicou a presença de $\mathrm{HCN}$ (o limite de detecção é de $0.25 \mu \mathrm{g}$ ) .

Teste de picrato: Material vegetal $(10 \mathrm{~g})$ moído foram colocados em um frasco de erlenmeyer, com $3 \mathrm{ml}$ de $\mathrm{HCl} 0,5 \mathrm{~N}$ e água $(10 \mathrm{ml})$. Este foi a seguir tampado com rolha de cortiça ou borracha à qual se fixou papel de filtro impregnado com solução de ácido pícrico e carbonato de sódic. A presença de $\mathrm{HCN}$ fol comprovada pela mudança da cor do papel, de amarelo a laranja e finalmente a vermelho ou vermelho escuro, após $20 \mathrm{~h}$, a $35^{\circ} \mathrm{C}$.

A determinação quantitativa do $\mathrm{HCN}$ nos capins foi feita pelo seguinte método: $50 \mathrm{~g}$ da planta, foi homogeneizada em liquidificador com $300 \mathrm{ml}$ de água à $4^{\circ} \mathrm{C}$, e deixada em autólise a temperatura ambiente por 20h. Após este período adicionou-se $10 \mathrm{ml}$ de $\mathrm{HCl}$ IN e efetuou-se o arrastre com vapor da água. O destilado $(500 \mathrm{ml})$ foi coletado em $\mathrm{NaOH} 0,7 \mathrm{M}$. Alíquotas $(50 \mathrm{ml})$ deste destilado foram tituladas com $\mathrm{AgNO}_{3} \mathrm{O}, \mathrm{OIN}$, após adição de $4 \mathrm{ml}$ de $\mathrm{NH}_{4} \mathrm{OH} I 3 \mathrm{M}$ e $2 \mathrm{ml}$ de $\mathrm{KI} 0,3 \mathrm{M}$ (Bruijn, 1971).

\section{CARACTERÍSTICAS gERAIS DAS PLANTAS}

\section{Axonopüs compressus (Swartz) Beauv. (Gramineae) "grama"}

Erva perene, rasteira, própria para formação de pastos e fixação de solos. Colmos florais eretos, não excedendo a $50 \mathrm{~cm}$ de altura, inflorescência formada de 2-5 espigas; colmos (estacas) reptantes achatados, que se alastram em todas as direções, formando denso gramado. Folhas estreitas, $2-6 \mathrm{~mm}$ de largura, obtusas no ápice, bainha com a base arroxeada.

Segundo Aplin (1975) é muito resistente ao pisoteio, ao fogo e ao frio, adaptando-se também em todos os tipos de solo, mesmo nos arenosos, com pouca umidade. Os climas quentes e úmidos são os que mais lhe convêm.

Multiplica-se por sementes, mudas enraizadas e pedaços de colmos.

Vegeta em estado espontâneo na Argentina e na África.

2. Brachiaria mutica (Forsk.) Stapf. (Gramineae)

"capim colônia"

Sinônimos botânicos: Bracriaria purpurascens (Raddi) Henr., Panicum purpurascens Raddi, Chaetochloa purpurascens Scrib \& Merr., Panicum barbinode Trin., Panicum equinum Salzm.. Setaria gracilis H.B.K. var. purpurascens H.B.K., Setaria purpurascens H.B.K.

Erva perene, estolonífera, colmos espessos, decumbentes, nós densamente pilosos. Folhas lineares, bainha longa. Inflorescência em panículas de rácemos alongados; espiguetas arroxeadas.

Há diversidade quanto à origem da espécie, porém, alguns autores, entre eles Aplin (1975) consideram-na originária da África tropical. No Brasil é encontrada desde o Amazonas até o Rio Grande do Sul (Monteiro et al., 1974). Prefere os solos férteis com bom teor de umidade, suportando bem o excesso de água nos locais inundados, porém cresce também nas capoeiras e terrenos altos. É muito tolerante a condições ambientais diversas, e, na região Amazônica é considerada como uma das principais forrageiras.

3. Cynodon dactylon (L.) Pers. (Gramineae) "grama de burro"

Erva perene, colmos eretos, reptantes e rizomatosos, enraizando-se facilmente nos nós, atingíndo $4-5 \mathrm{~m}$ de comprimento, cobrindo ra- 
pidamente o solo, sendo por esta razão muito utilizada em praças e jardins públicos. Folhas linear-lanceoladas, setosas. Inflorescência com 2-6 espigas digitadas saindo do ápice de colmo florífero.

Originária da Índia, segundo Mattos (1967), foi introduzida no Brasil no período colonial, alastrando-se em toda a sua área e, apesar de considerada boa forragem, constitui uma das piores pragas da lavoura.

Muito resistente ao fogo, ao pisoteio e também à seca, não suporta porém temperaturas muito baixas (Otero, 1952). Vegeta em quase todos os tipos de solo, mesmo nos arenosos (Le Cointe, 1947), sendo por isso indicada para fixar terrenos em declive a fim de evitar erosões. No Campus do INPA é espontânea, em solo argiloso.

De fácil propagação, multiplica-se por sementes, mudas em pedaços de colmos.

$\mathrm{Na}$ bibliografia especializada é citada como boa forrageira, principaimente para cavalos. No entanto, Aplin (1975) menciona um record de envenenamento na Austrália, atribuído a esta espécie, quando 29 ovelhas morreram com evidentes sinais de cianose.

4. Eleusine indica (L.) Gaertn. (Gramineae) "capim pé de galinha"

Sinônimos botânicos: Cynosurus indicus L., Eleusine distachya Trin., E. distans Moench., E. domingensis Sieber, E. gonantha Schrank, E. tristachya Schrank, Panicum compressum Forsk.

Erva cespitosa, perene ou anual, de origem asiática segundo Mattos (1967), atingindo 20-30 (40) $\mathrm{cm}$ de altura; colmos eretos, curtos; nós pilosos. Folhas estreitas, linear-lanceoladas, esparsamente pilosas na face inferior, escabras na face superior; bainha glabra; lígula membranácea, pilosa. Inflorescência longopedunculada formada de espigas fasciculadodigitadas, 3,6 ou mais, lineares, flexíveis; espiguetas sésseis, comprimidas, em ambos os lados do raque.

Comum na região tropical, segundo Aplin (1975) é também encontrada no sudoeste da Austrálía. Cosmopolita, espontânea ou subespontânea em todas as regiões tropicais do globo; segundo Pio Corrêa (1926), no Brasil se encontra em toda parte. Na Amazônia, cresce espontaneamente em solo argiloso, nas capoeiras, próximo de habitações, jardins ou lugares antes cultivados.

5. Echinochloa spectabile (Nees) Link (Gramineae. "canarana verdadeira"

Sinônimos botânicos: Echinochloa polystachya Hitch., Oplismenus spectabile Kunth, Panicum jamaicense Steud., Panicum spectabile Nees.

Erva espontânea ou subespontânea, perene, subaquática, desenvolvendo-se exuberantemente à margem dos rios e lagos, em terrenos alagados, formando associaçöes densas, obstruindo muitas vezes os cursos d'água, impedindo até a navegação. Colmos eretos ou decumbentes, grossos, até $2 \mathrm{~m}$ de comprimento, glabros, os nós pilosos ou subglabros; bainha foliar estriada, glabra; lígula às vezes ciliada. Folhas lanceoladas, glabras, margem ligeiramente denteada ou serrilhada. Inflorescência em panícula estreita, ereta, composta de espigas solitárias ou aos pares; espiguetas pedunculadas, esverdeadas ou violáceas, com aristas longas.

Comumente citada na literatura como ótima forrageira para o gado bovino, principalmente, ocorre espontaneamente na Amazônia e Guiana, e segundo Pio Corrêa (1931) também nos Estados do Ceará, Bahia, S. Paulo, Rio Grande do Sul e Mato Grosso, onde é menos freqüente.

6. Homolepis atuarensis (H.B.K.) Chase (Gramineae)

"capim pacuã", "capim papuã", "capim amargoso".

Erva rasteira, algumas vezes escandente sobre a vegetação vizinha, comum nas margens das estradas, em solo geralmente argiloso e não muito seco. Estolonífera, propagando-se facilmente pelos nós, forma enormes cordões que cobrem rapidamente o solo. Folhas elítico-lanceoladas ou lineares, pubescentes, de ápice agudo e base cordiforme. Inflorescência em panícula terminal espiciforme; espigas sub-fusiformes, curtas; espiguetas com pedicelos delgados. Fruto cariópse elítica, aguda, glabra, comprimida no dorso. 
Reproduz-se por sementes ou vegetativamente, e, segundo Cárdena et al., (1972) esta espécie é tóxica, causando nocividade secundária.

\section{Hymenachne amplexicaulis (Rudge) Nees} (Gramineae)

Sinônimos botânicos: Panicum amplexicaule Rudge, Agrostis monostachya Poir, Panicum hymenachne Desv.

Erva aquática com os nódulos inferiores radicantes e colmo robusto. Comum nos terrenos baixos em tempo de inverno, constitui com outros as ilhas flutuantes do Amazonas. Folhas longas, lanceoladas de ápice agudo e base cordada, glabra e bainha fortemente amplexicaule. Infiorescência em panículas alongadas, densas, espiciformes, com espiguetas curtamente pediceladas; espiguetas acuminadas.

É considerada como forragem excelente para o gado bovino.

\section{Oryza perenis Moench.(") (Gramineae) \\ "amor selvagem"}

Gramínea herbácea de 1,5-2m de altura, comum nos lugares úmidos ou mesmo alagados, em geral nas várzeas e beira dos rios, formando aglomerados densos nos locais pouco profundos. Folhas longas, planas, largas, linear-lanceoladas, com lígulas pilosas. Inflorescência em panículas longas, eretas constituídas de espigàs compridas, delgadas, verdes com espiguetas unifloras pediceladas; pedicelo curto comprimido, dilatado no ápice. Fruto cariópse oblongo-comprimida, inclusa nas glumelas rígidas, obtusa ou aguda no ápice, aristada.

$\mathrm{Na}$ América do Sul ocorre no Brasil, Peru, Colômbia e Guiana Francesa.

9. Panicum chloroticum Nees. (Gramineae)

Sinônimos botânicos: P. dichotomiflorum Mchx., P. hygrophilum Salzm., Setaria brachiata Kunth.

Erva muito ramificada na base, colmos geniculados, ascendentes, um pouco comprimidos, foliosos, estriados, glabros, simples ou ramificados, nós glabros, violáceos; bainhas foliares estriadas; lígula membranácea muito curta, ciliada. Folha linear-lanceolada, glabra, escabrosa nas margens e página superior, lisa na inferior. Inflorescência composta, paniculada, subcorimbiforme, multiflora, ereta; espiguetas imbricadas, agudas; glumas (2) herbáceas. Fruto cariopse ovóide, comprimida.

No Brasil, ocorre desde a Amazônia até o Rio de Janeiro (Pio Corrêa, 1931), porém, possivelmente, ocorre ainda mais para o sul.

10. Panicum maximum Jacq.

"capim de Guiné"; "capim de Angola"; "capim colonial"; "capim colônia"; " capim de touceira"; outros...

Sinônimos botânicos: Panicum altissimum Brouss., P. confusum Trin., P. jumentosum Pers., P. polyganum Jacq.. P. trichocondylum Steud.

Erva perene formando touceiras densas, crescendo até 2,50 (3) $\mathrm{m}$ de altura; florescendo e frutificando várias vezes no ano; colmos eretos, cilíndricos, glabros com a base em geral tuberosa, vilosos nos nós; lígula ciliada; lâmina linear, glabra em ambas as faces. Inflorescência terminal, ramificada, ramos filiformes, com numerosas espiguetas, glabras, com máculas violáceas ou inteiramente violácea ainda imatura, fungínea quando madura.

Originária da África, porém, cultivado em todo o Brasil, presta-se, segundo Otero (1952), para ser cortado e distribuído como forragem verde aos animais, devendo ser cortado ao atingir $1-1,5 \mathrm{~m}$ de altura, portanto, antes de florescer, quando ele atinge o seu máximo desenvolvimento, tornando-se inclusive bastante lignificado. E considerado como boa forragem, pouco exigente quanto ao solo, vegetando bem em qualquer tipo, desde que sejam úmidos. $\mathrm{Na}$ Amazônia é cultivado em terra firme, em solo um pouco arenoso, não muito seco. Segundo Le Cointe (1947), $1 \mathrm{~km}^{2}$ plantado destas gramíneas sustenta 300 reses.

Taxonomicamente, segundo Otero (1952), existem diversas variedades destas gramineas.

$\left(^{\bullet}\right)$ - Nome de aplicaçäo possivelmente incerta, segundo Takeoka (1963). 


\section{Panicum pilosum Swartz.}

Erva cespitosa de $20-50(100) \mathrm{cm}$ de altura, comum nos lugares abertos nas margens das estradas, em capoeiras recentes e em lugares bastante úmidos ou mesmo inundados, formando associações densas. Folhas linear-lanceoladas, estreitas, ápice agudo e base sub-turneado. Inflorescência longo-paniculada, muito delicada, de espigas delgadas e espiguetas muito pequenas curto-pediceladas.

12. Paspalum repens Berg.

"canarana rasteira"; "capim perimembeca".

Sinônimos botânicos: Ceresia fluitans Elliot, Cy. matochloa repens Schl., P. bistipulatum Hochs, P. grasile Rudge, P. mucronatum Muhl., P. pyramidale Nees.

Erva aquática, de colmo cilíndrico, fistuloso, estriado, até $1,5-2 \mathrm{~m}$ de altura, com os nós glabros e escuros. Folhas linear-lanceoladas, acuminadas, estriadas e pubescentes. Comum nos lugares baixos, úmidos e argilosos, formando as chamadas "ilhas flutuantes" no Amazonas.

Fornece forragem excelente tanto para bois e cavalos e recomendado especialmente para as vacas de leite (Pio Corrêa, 1926), porém perde rapidamente suas qualidades nutritivas após a frutificação. Folhas longas, estreitamente lanceoladas e inflorescências em panícula de espigas; espiguetas sésseis.

\section{Paspalum conjugatum Berg. (Gramineae) \\ "capim roxo"}

Sinônimos botânicos: Panicum bicrurum Salzm., P. ciliatum Lam., P. longissimum Hochst., P. sieberianum Steud., P. reuggeri Steud., P. tenue Gaertn.

Erva ruderal, perene, $20-30(40) \mathrm{cm}$ de altura, comum em toda a região tropical, e, segundo Aplin (1975) encontrada também na Austrália. Colmo principal prostrado, colmos secundários ascendentes; ambos estriados, glabros nodosos, nós escuros; bainha foliar estriada; lígula membranácea, ciliada; lâmina linear-lanceolada, acuminada, áspera nas margens, glabra ou subglabra. Inflorescência longo-pedunculada em geral formada de 2 espigas apicais conjugadas, raramente 3 , divergentes, lineares. De propagação e crescimento rápido, resiste ao pisoteio, ao sol intenso e ao fogo, vegetando mesmo em terrenos secos. Multipiica-se por sementes ou por pedaços de colmo.

$\mathrm{Na}$ Amazônia, ocorre em lugares de terra firme, nas capoeiras abertas, em solo arenosos ou argiloso. Segundo Le Cointe (1947), constitui boa forragem antes do amadurecimento das sementes, pois, quando maduras, aglomeram-se na boca dos animais, causandoIhes ferimentos na mucosa.

14. Penisetum purpureum Schum. (Gramineae) "capim elefante"

Sinônimos botânicos: Penisetum benthami Steud., P. macrostachyum Benth.

Erva perene, rizomatosa, até $3-4 \mathrm{~m}$ de altura, originária da África tropical porém amplamente cultivada no Brasil por ser de grande rentabilidade como forrageira. Colmos cilíndricos, compactos, com nós bastante salientes. Folhas alternas, invaginantes, de $1 \mathrm{~m}$ de comprimento, híspidas. Inflorescência em rácemos espiciformes longo-pedunculada, terminal ereta, de espiga solitária com espiguetas densamente pilosas, com 1-3 flores; arista setácea. Fruto cariópse oblonga, seca. Introduzida no Brasil desde 1921, produz, segundo alguns, excepcional forragem verde, resistincio fortemente às geadas e sobretudo às secas duradouras.

São conhecidas, segundo Otero (1952), duas variedades bem distintas deste capim, designadas por var. A e var. B, antes denobinadas de var. napier e var. mercker.

\section{Resultados}

\section{PLANTAS CIANOGENÉTICAS}

Com o intuito de indicar quais são os capins portadores de compostos cianogênicos que são utilizados na alimentação de animais, foram feiats primeiramente análises qualitativas para o $\mathrm{HCN}$, testes de acetado de benzidina e picrato de sodio e após determinações quantitativas (Tabela 1), análises feitos com 3 a 5 repetições das amostras coletadas nas condições descritas anteriormente. 
TABELA 1 - Conteúdo de HCN em Gramíneas

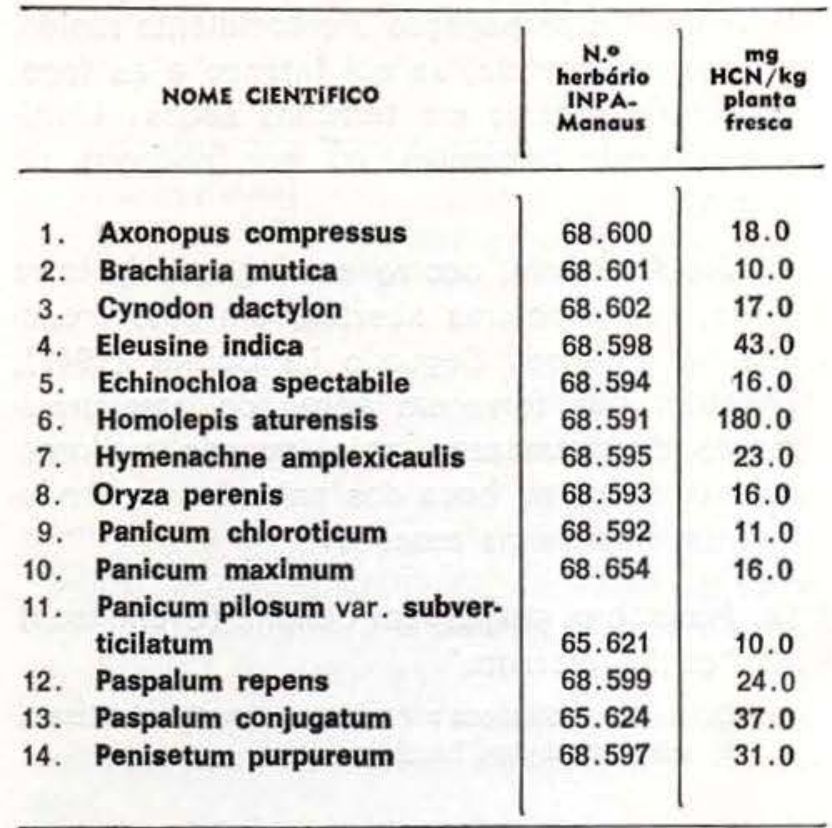

Ao mesmo tempo são apresentadas soluções simples para a eliminação do HCN (Aplin, 1975) por tratamentos físicos (corte, secagem e volatilização parcial, para isto foram feitos ensaios de eliminação de HCN (Tabela 2) efetuando-se nos tratamentos indicados, análises químicas sucessivas, testes de picrato, em tempos acrescentes até obter o desaparecimento do $\mathrm{HCN}$ indicado por uma reação negativa do teste.

TABELA 2 - Eliminação do HGN em Gramíneas

\begin{tabular}{|c|c|c|c|c|}
\hline & NOME CIENTIFICO & $\begin{array}{c}\text { Seca- } \\
\text { gem a } \\
\text { 1000C } \\
\text { (horas) }\end{array}$ & $\begin{array}{c}\text { Tempera- } \\
\text { tura de } \\
\text { laborató- } \\
\text { rio (250C) } \\
\text { (dias) }\end{array}$ & $\begin{array}{l}\text { Fervura } \\
\text { (hora) }\end{array}$ \\
\hline 1. & Axonopus compressus & 3 & 25 & 1 \\
\hline 2. & Brachiaria mutica & 8 & 25 & 1 \\
\hline 3. & Cynodon dactylon & 30 & 25 & 4 \\
\hline 4. & Eleusine indica & 10 & 25 & 2 \\
\hline 5. & Echinochloa spectabile & 3 & 25 & 4 \\
\hline 6. & Homolepis aturensis & 37 & 50 & 10 \\
\hline 7. & Hymenachne amplexicaulis & 3 & 25 & 1 \\
\hline 8. & Oryza perenis & 6 & 25 & 1 \\
\hline 9. & Panicum chloroticum & 6 & 25 & 4 \\
\hline 10. & Panicum maximum & 2 & 25 & 2 \\
\hline 11. & $\begin{array}{l}\text { Panicum pilosum var. } \\
\text { subverticilatum }\end{array}$ & 12 & 25 & 2 \\
\hline 12. & Paspalum repens & 4 & 25 & 3 \\
\hline 13. & Paspalum conjugatum & 41 & 25 & 4 \\
\hline 14. & Penisetum purpureum & 8 & 25 & 1 \\
\hline
\end{tabular}

Os ensaios de eliminação de $\mathrm{HCN}$ foram feitos somente para os capins, por serem eles tradicionalmente indicados como forragem para bovinos e eventualmente outros animais, as outras plantas mesmo comprovadamente cianogenéticas (Tabela 3) deixam de oferecer perigo aos animais, pela pequena probabilidade de serem ingeridos.

TABELA 3 - Outras plantas cianogenéticas

\begin{tabular}{l|l|l}
\hline \multicolumn{1}{c|}{ Nome científico } & Família & Nome vulgar \\
\hline 1. $\begin{array}{l}\text { Hevea brasiliensis } \\
\text { Nüll Arg. }\end{array}$ & $\begin{array}{l}\text { Euphorbla- } \\
\text { ceae } \\
\text { Euphorbia- } \\
\text { 2. Manihot spp. }\end{array}$ & Seringa (eira) \\
3. Ouratea sp. & $\begin{array}{l}\text { Ochnaceae } \\
\text { Passiflora- } \\
\text { ceae }\end{array}$ & $\begin{array}{l}\text { Maracujá de } \\
\text { rato }\end{array}$ \\
4. Passiflora coccinea \\
$\begin{array}{l}\text { Aubl. } \\
\text { 5. Prunus myrtifolia ( ) } \\
\text { Urb. }\end{array}$ & $\begin{array}{l}\text { Rosaceae } \\
\text { 6urnera hilairiana } \\
\text { var. minor Urb. }\end{array}$ & Truneraceae \\
7. $\begin{array}{l}\text { Vismia cayenensis } \\
\text { Pers. }\end{array}$ & Guttiferae & Lacre \\
\hline
\end{tabular}

A (Tabela 4) indica os capins testados como não cianogênicos após testes de acetado de benzidina e de picrato de sódio.

TABELA 4 - Capins testados com resultado negativo para $\mathrm{HCN}$

\begin{tabular}{|c|c|}
\hline Nome científico & Família \\
\hline $\begin{array}{l}\text { Andropogon leucostachyus H.B.K. } \\
\text { Brachiaria decumbens Stapf. } \\
\text { Cyperus diffusus Vahl. subsp. cha- } \\
\text { laranthus (Prest.) Kuck. } \\
\text { Digitaria horizontalis Willd. } \\
\text { Dichromena ciliata (Vahl.) Kuch. } \\
\text { Panicum rudgei Roem. et Schult. } \\
\text { Scleria pratensis Lindl. } \\
\text { Setaria sp. } \\
\text { Trichachne insularis Nees }\end{array}$ & $\begin{array}{l}\text { Gramineae } \\
\text { Cyperaceae } \\
\text { Gramineae } \\
\text { Cyperaceae } \\
\text { Gramineae }\end{array}$ \\
\hline
\end{tabular}




\section{CONCLUSÕES}

Tendo-se testado algumas gramíneas dada sua importância de serem usadas como forrageiras, encontrou-se dentro das espécies estudadas algumas cianogênicas, sendo o Homolepsis auturensis a que apresentou o maior teor de $\mathrm{HCN}$ e de mais difícil eliminação, podendo ser esta uma das causas de intoxicações que vem ocorrendo nesta região. Isto não exclui, porém, a possibilidade de que os outros capins testados como cianogênicos, possam apresentar riscos de intoxicações, dado que o teor de ácido cianídrico está ligado a fatores fisiológicos e genéticos (Butler et al., 1973), podendo apresentar-se condições naturais que favoreçam a sintese de glucosídios cianogênicos da planta.

Sugere-se, portanto, testar e controlar o teor e a eliminação destes glucosídios, nas gramíneas citadas como cianogênicas, antes de serem ingeridas pelos animais.

\section{SUMMARY}

Data concerning the hydrocyanic acid content of 14 grasses and physical methods for its elimination are presented, together with some botanical details of these and other Amazonian plants.

\section{BIBLIOGRAFIA CITADA}

APLN, T.E.H.

1975 - Cyanogenetic plants of western Australia. Bull Western Australiam Department of Agriculture, (3967) : 1-14

BRULIN, G.H. DE

1971 - Etude de caractère cyanogénétique du manioc (Manihot esculenta Grantz). Mededelingen Landbouwhogeschool, Wageninggen, p. 71-73.

BUtler, G.W.; RAY, P.F. \& TAPPER, B.A.

1973 - Physiological and genetics aspects of cyanogenesis in cassava and other plants. London: International Development Research Centre. Monograf; IRDC010e, p. 65-71.
CÁRdena, J.; Reyes, C.E. \& DOLL, J.D.

1972 - Tropical Weeds. Malezas Tropicales. Vol. 1. Bogotá, p. 25.

EyJoLFSSON, R.

1970 - Recent advances in the chemistry of cyanogenic glycooides. Fortsch. Chem. Org. Nat., $28: 74-108$.

JONES, D.A.

1972 - Cyanogenic glycosides and their function, p. 103-104. In: Harbone B. ed. Phytoche. mical Ecology, London, Academic Press.

LE COINTE, P.

1947 - Amazônia Brasileira III. Árvores e plantas úteis, (Indigenas e aclimatadas). 2 ed. S. Paulo, Ed. Nacional, 506 p. il. (Brasiliana 251).

Matros, J.R.

1967 - Chlorideae do Est, de S. Paulo. Gramineae. Serv. Inf. Agric., Minist. Agric. Rio de Janeiro. Estudos Tecnológicos, $35: 14$ fig.

Mirolajczak, K.L.

1977 - Cyanolipids. Progress in the Chemistry of Fats and other Lipids. Vol. 15, p. 97-130. Great Britain, Pergamon,

Monteiro, M.C.C.; Lucas, G.D. DE \& Souto, S.M.

1974 - Estudo de seis espécies forrageiras do gênero Brachiaria. Pesq. agropec. bras., Sér. Zootecn., $9: 17-20$.

OTERO, J.R. DE

1952 - Informaçōes sobre algumas plantas forrageiras. Serviço de informação agrícola. Série didática, 11, Rio de Janeiro. $313 \mathrm{p}$.

PIO CORRÊA, M.

1926 - Dicionário das Plantas úteis do Brasil e das exóticas cultivadas. Rio de Janeiro. Ministério da Agricultura. Vol, 1, p. 505-654.

SEIGLER, D.S.

1975 - Isolation and characterization of naturally occurring cyanogenic compounds. Phytochemistry, 14:9-29.

TAKEOKA, T.

1963 - Taxonomic studies of Oryza III. Key to the species and their enumeration. Bot. Mag. Tokyo, 76:165-173.

(Aceito para publicação em 22-02-78) 